\title{
Plasma Somatostatin Response in Normal and Gastrectomized Subjects
}

\author{
Taro Wasada* $†$ Yoshifumi Kodama, $\ddagger$ Kaoru Inoue, ${ }^{*}$ \\ Akitaka Hisatomi, ${ }^{*}$ Yasuhiro Sako* and Hiroshi \\ IBAYASHI* \\ *The Third Department of Internal Medicine, Faculty of \\ Medicine, Kyushu University, Fukuoka 812 and $\ddagger$ the \\ Second Department of Surgery, Faculty of Medicine, \\ Fukuoka University, Fukuoka 814-01
}

\begin{abstract}
Wasada, T., Kodama, Y., Inoue, K., Hisatomi, A., Sako, Y. and Ibayashi, H. Plasma Somatostatin Response in Normal and Gastrectomized Subjects. Tohoku J. exp. Med., 1986, 150 (2), 181-188 — The present work was undertaken to investigate a possible contribution of the stomach to plasma concentrations of somatostatin-like immunoreactivity (SLI) in humans. For this purpose, plasma SLI responses were determined in previously gastrectomized subjects during lipidheparin induced elevation of plasma free fatty acids (FFA), which gave a consistent rise of plasma SLI in normal controls. Fasting plasma SLI levels in both the subjects with antral and total gastrectomy did not differ from the values in normal controls. Acute elevation of plasma FFA resulted in about 5-fold increase of plasma SLI above basal level in the controls. In contrast, in both the gastrectomy groups there was no significant rise in plasma SLI, despite a comparable elevation of plasma FFA levels. In conclusion, these findings demonstrate that the stomach, probably the antral region of the stomach, accounts for the most part of increase of plasma SLI when hyperfatty-acidemia is induced and suggest that following the stimulation by nutrients the stomach makes a greater contribution to plasma SLI levels than does the pancreas or extragastric intestinal tract in humans.

plasma somatostatin-like immunoreactivity; gastrectomized subject; nutrient stimuli ; FFA
\end{abstract}

Somatostatin-like immunoreactivity (SLI) increases in human peripheral venous blood in response to ingestion of food and parenteral administration of various nutrients (Wass et al. 1980 ; Conlon et al. 1983 ; Beylot et al. 1984 ; Skare et al. 1984). Thus, somatostatin may play a role in the regulation of certain gastrointestinal functions and in the homeostasis of ingested nutrients. Regarding the sources of circulating SLI, several lines of evidence indicate that the D cells of the pancreas and gastrointestinal tract are responsible for plasma SLI concentrations (Schusdziarra et al. 1978, 1981). However, the relative importance

Received June 30, 1986; accepted for publication September 6, 1986.

$\dagger$ Present address: Tokyo Women's Medical College, Diabetes Center, 10 Kawada-cho, Shinjuku-ku, Tokyo 162. 
of each organ is poorly understood in human. Recently, Taborsky and Ensinck (1984) provided the evidence that the pancreas made a negligible contribution, as compared with the gastrointestinal tract, to plasma SLI concentrations in both basal and stimulated states in normal dogs. The present study was intended to clarify the contribution of stomach to plasma SLI concentrations by measuring plasma SLI changes during lipid-heparin induced plasma FFA elevation in previously gastrectomized subjects with an intact pancreas.

\section{Subjects and Methods}

\section{Subjects}

The present study included 10 healthy volunteers, aged 20-57 years (mean age 42.6 years), 5 subjects who had undergone partial (antral) gastrectomy, aged 30-60 year (44.0 year), and 6 subjects undergone total gastrectomy, aged 40-64 year (55.8 year). The clinical parameters of these subjects are presented in Table 1. All the gastrectomized subjects had a curative operation and had been found to have an intact pancreas during laparotomy. They appeared to be in good health at the time of study. The control subjects were within $10 \%$ of ideal body weight and had no metabolic disorders.

\section{Experimental protocol}

In the first set of experiments, each of 5 healthy men, aged 20-24 year, received four differerent tests given alternatively on separate days.

Oral glucose test (OGT). The subjects received $225 \mathrm{ml}$ of $33 \%$ dextrose solution flavored with lemon essence (Trelan- $G{ }^{\circledR}$, Shimizu Pharmaceutical Co., Shizuoka) by mouth.

Mixed meal test (meal test). The subjects received $200 \mathrm{ml}$ of liquid test meal (protein $9.8 \mathrm{~g}$, fat $5.2 \mathrm{~g}$, carbohydrate $28.6 \mathrm{~g}, 200 \mathrm{Kcal}$, Okunos ${ }^{\circledR}$, Okuno Co., Tokyo).

Arginine infusion test (AIT). The subjects received $300 \mathrm{ml}$ of $10 \% \mathrm{~L}$-arginine monohydrochloride ( $\mathrm{pH}$ 5.0-6.0, Morishita Pharmaceutical Co., Osaka) by an intravenous drip infusion over $30 \mathrm{~min}$.

Intrafat ${ }^{\circledR}$ plus heparin test (lipid-heparin test). The subjects received an i.v. infusion of $10 \%$ Intrafat Injection ${ }^{\circledR}$ (fractionated soya oil $10 \mathrm{~g}$, fractionated ovolecithin $1.2 \mathrm{~g}$, glycerin $2.5 \mathrm{~g} / 100 \mathrm{ml}$, Daigo Nutritional Chemistry Co., Osaka) at a rate of $1 \mathrm{ml} / \mathrm{min}$ over 120 min and additionally 3 injections of $2000 \mathrm{U}$ heparin sodium (Novo Ind., Denmark) at a time indicated in Figs. 2 and 3 during lipid infusion.

In the second set of experiments, 5 partially gastrectomized subjects and 6 totally gastrectomized subjects as well as 10 normal controls participated in the lipid-heparin test.

All the experiments were performed under the basal state after an overnight fast and blood samples were drawn via a stopcock-equipped catheter which was placed in the antecubital vein and kept patent with a slow drip infusion of isotonic saline solution. The test solution was infused into an opposite antecubital vein. Blood was collected into the chilled tube containing $6 \mathrm{mg}$ EDTA and $500 \mathrm{KIU}$ Trasylol $/ \mathrm{ml}$ of blood. The samples were centrifuged at $4^{\circ} \mathrm{C}$ and plasma was stored at $-20^{\circ} \mathrm{C}$ until assay.

\section{Assay of plasma SLI}

Plasma SLI was measured by the identical method previously described (Conlon et al. 1983). In brief, plasma was treated with $30 \%$ (W/V) polyethylene glycol 6,000 (final concentration $13.3 \%$ ) and mixture was centrifuged at $3,000 \mathrm{rpm}$ for $60 \mathrm{~min}$ at $4^{\circ} \mathrm{C}$. An aliquot of supernatant was used for radioimmunoassay. Synthetic cyclic somatostatin-14 (Peptide Institute Co., Osaka), ${ }^{125} \mathrm{I}_{-} \mathrm{Tyr}^{11}$-somatostatin-14 (Amersham international plc, Buckinghamshire, U.K.) and anti-somatostatin-14 serum $80 \mathrm{C}$ from R.H. Unger (University of Texas, Dallas, TX, USA) were used. The anti-serum $80 \mathrm{C}$ (final dilution $1: 150,000$ ) also 


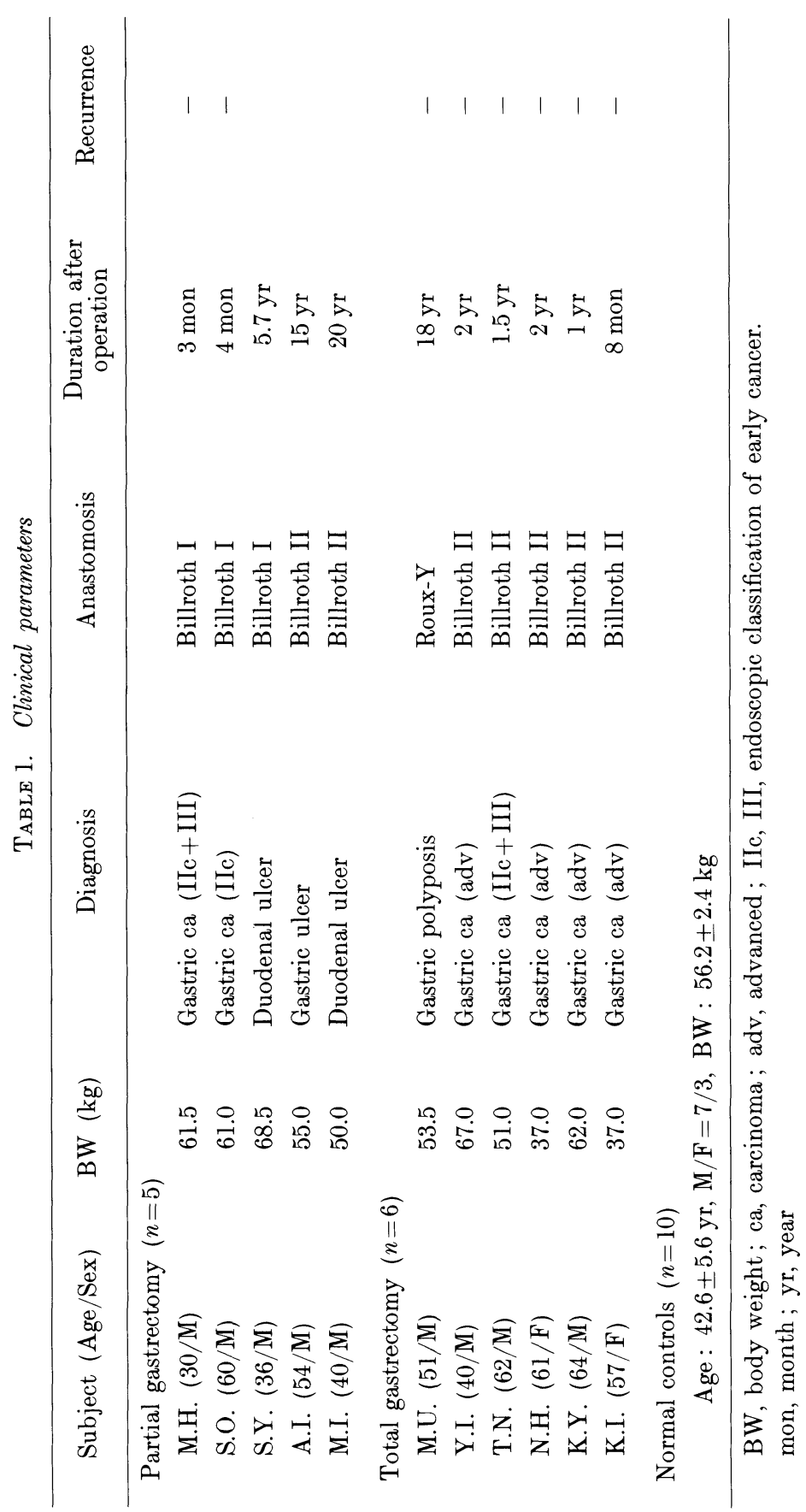




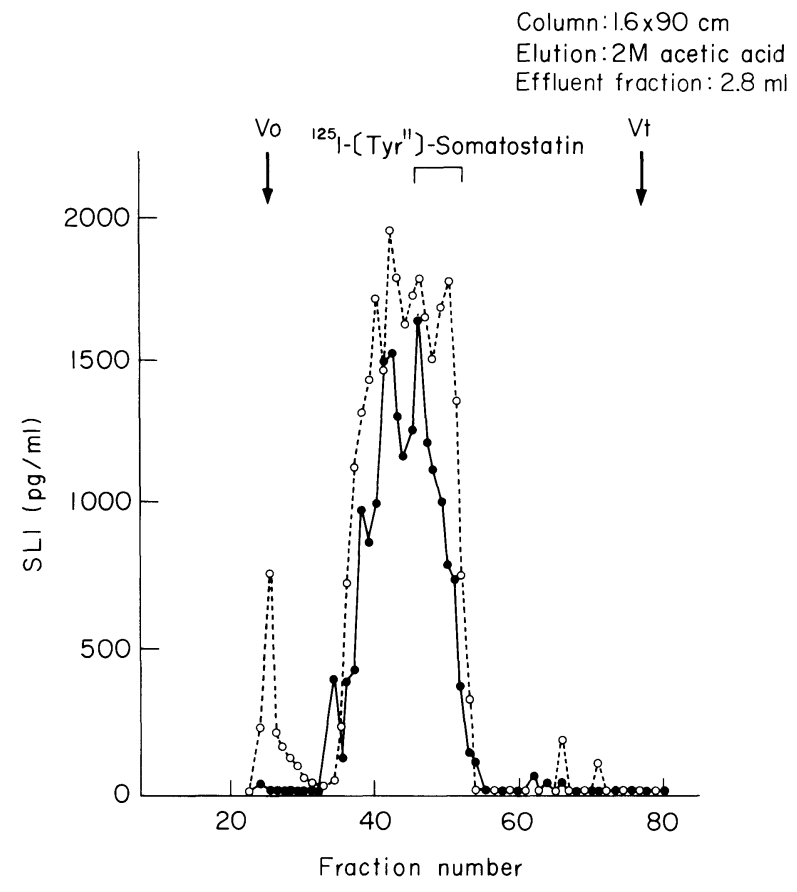

Fig. 1. Gel filtration chromatography of plasma containing a high level of injected synthetic SS-14. Two ml of plasma were chromatographed on a Sephadex G-25 (fine) column $(1.6 \times 90 \mathrm{~cm})$ equilibrated with $2 \mathrm{M}$ acetic acid $(\mathrm{pH} 2.5)$ containing $0.1 \%$ BSA. Eluates were assayed for SLI before $(\bigcirc \cdots \cdots)$ and after $(\bullet)$ treatment with PEG. The column was calibrated with blue dextran $\left(\mathrm{V}_{0}\right),{ }^{125} \mathrm{I}-\mathrm{Tyr}^{11}$-Somatostatin- 14 , and $\mathrm{Na}^{125} \mathrm{I}(\mathrm{Vt})$ as indicated in the figure.

detects somatostatin-28 equally well on a molar basis. Plasma SLI concentrations were determined by reference to a somatostatin-14 standard.

To validate the assay regarding the void volume SLI which constitutes the predominant circulating SLI component and reportedly represents an artifact of measurement (Conlon et al. 1982), a plasma specimen containing high level of injected synthetic somatostatin-14 was gel chromatographed on Sephadex G-25 (fine) column $(1.6 \times 90 \mathrm{~cm})$ and eluates were measured for SLI. As shown in Fig. 1, the void volume peak was almost totally eliminated when eluates were treated with PEG before assay. The minimal sensitivity of this assay is $7.8 \mathrm{pg} / \mathrm{ml}$ for plasma and $3.9 \mathrm{pg} / \mathrm{ml}$ for eluates. The values under these levels were read off automatically from the computer-fitted standard curve. The intra-assay and inter-assay coefficient of variation at the level of $30-40 \mathrm{pg} / \mathrm{ml}$ were $9.6 \%$ and $15.2 \%$, respectively.

FFA measurements

Plasma FFA concentrations were determined by the enzymatic method consisting of acyl-CoA synthetase, acyl-CoA oxidase and peroxidase system (Shimizu et al. 1980).

\section{Data analysis}

The data are expressed as mean \pm S.E. Paired $t$-tests were used to evaluate the statistical significance between a value at certain time and a basal (or average of basal) value. 

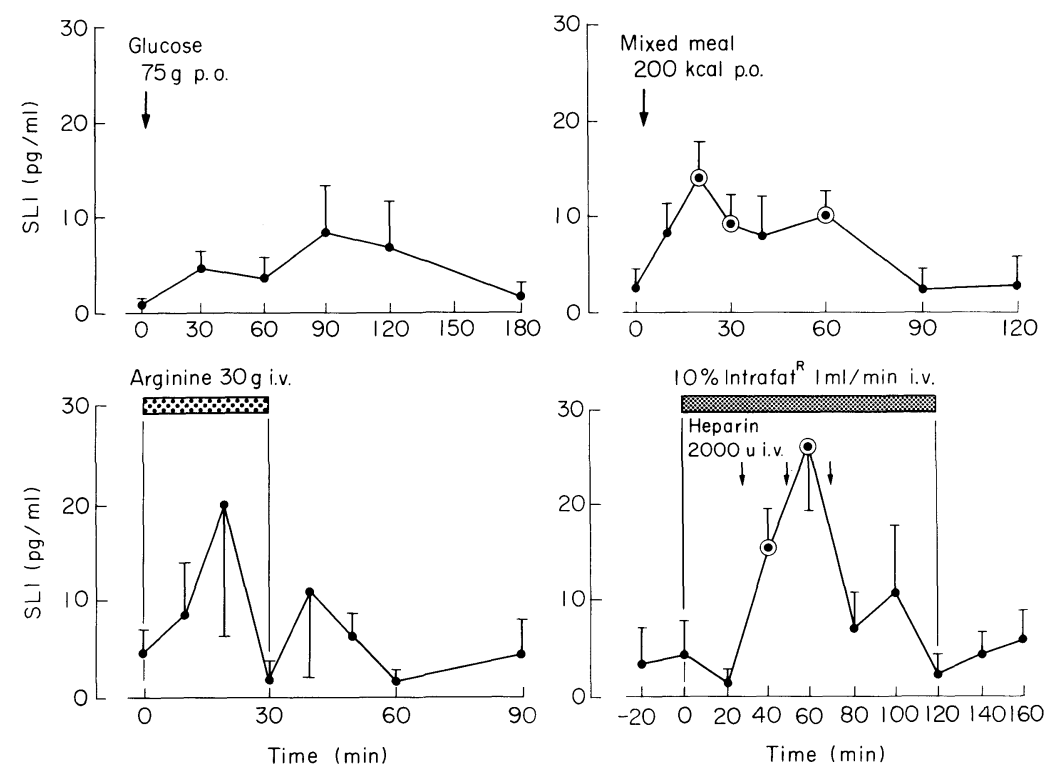

Fig. 2. Comparison of stimulating potency of glucose, arginine, mixed meal, and FFA for secretion of SLI in 5 identical healthy subjects. Mean \pm s.E.
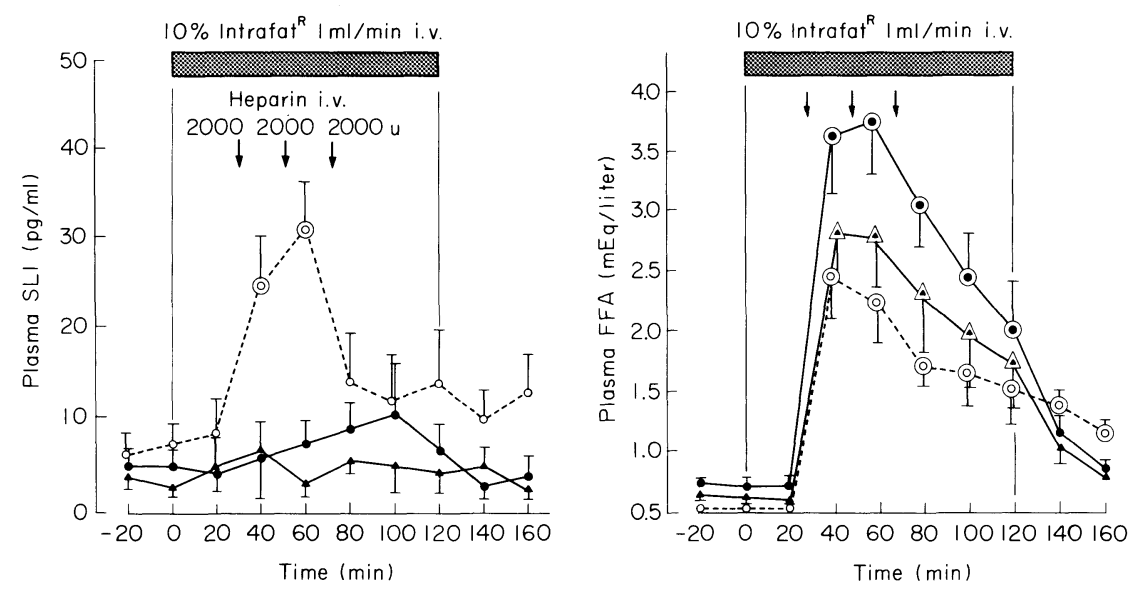

Fig. 3. Response of plasma SLI (left) and plasma FFA (right) during lipidheparin test in normal $(\bigcirc, n=10)$, partial gastrectomized $(\triangle, n=5)$, and total gastrectomized $(\bullet, n=6)$ subjects. No significant difference was found in plasma FFA levels among the three groups, but SLI response was significantly higher $(p<0.05)$ in the control group at 40 and $60 \mathrm{~min}$, compared with the gastrectomized groups. Double symbols represent a significant $(p<0.05$ or less) rise above the baseline (or mean baseline) level. Mean \pm s.E.

\section{RESULTS}

To compare a relative stimulating potency among nutrients for secretion of SLI, 5 controls received 4 different tests in randomized order at least 3 days apart 
from the previous test (Fig. 2). Oral glucose (Panel A) was followed by an insignificant SLI response over $180 \mathrm{~min}$ after glucose ingestion. In AIT (Panel B), 2 of the 5 subjects responded markedly, but no statistically significant increase was noted as a whole group. In meal test (Panel C), plasma SLI showed rather small, but significant $(p<0.05)$, increase at 20,30 and $60 \mathrm{~min}$ after ingestion of test meal from a baseline of $2.6 \pm 2.0 \mathrm{pg} / \mathrm{ml}$ to $13.9 \pm 3.5 \mathrm{pg} / \mathrm{ml}, 9.6 \pm 2.9 \mathrm{pg} / \mathrm{ml}$, $10.2 \pm 2.1 \mathrm{pg} / \mathrm{ml}$, respectively. In lipid-heparin test (Panel D), plasma SLI rose significantly $(p<0.05)$ at 40 and $60 \mathrm{~min}$ from the mean baseline of $3.9 \pm 3.2 \mathrm{pg} / \mathrm{ml}$ to $15.4 \pm 3.9 \mathrm{pg} / \mathrm{ml}$, and $25.7 \pm 6.4 \mathrm{pg} / \mathrm{ml}$, respectively. These increases coincided with the significant $(p<0.01)$ elevation of plasma FFA which was followed by heparin injection from the mean baseline of $0.31 \pm 0.04 \mathrm{mEq} /$ liter to $2.16 \pm 0.25$ $\mathrm{mEq} /$ liter at $40 \mathrm{~min}$, and $1.75 \pm 0.3 \mathrm{mEq} /$ liter at $60 \mathrm{~min}$, respectively.

Fig. 3 shows the comparison of plasma SLI response to plasma FFA elevation in the normal and in the gastrectomized subjects. A sharp rise of plasma FFA was found in all the groups ; in the normal controls from mean baseline of $0.41 \pm$ $0.06 \mathrm{mEq} /$ liter to a peak value of $2.40 \pm 0.32 \mathrm{mEq} /$ liter $(p<0.01)$ at $40 \mathrm{~min}$, in the partial gastrectomized subjects from $0.66 \pm 0.15$ to $2.81 \pm 0.42 \mathrm{mEq} / \mathrm{liter}(p<0.01)$ at $40 \mathrm{~min}$, and in the total gastrectomized subjects from $0.72 \pm 0.09$ to $3.75 \pm 0.44$ $\mathrm{mEq} /$ liter $(p<0.01)$ at $60 \mathrm{~min}$, respectively. On the other hand, plasma SLI in the normal controls rose from the mean baseline of $6.5 \pm 2.3 \mathrm{pg} / \mathrm{ml}$ to $24.7 \pm 5.3 \mathrm{pg} /$ $\mathrm{ml}(p<0.05)$ at $40 \mathrm{~min}$ and $31.0 \pm 5.4 \mathrm{pg} / \mathrm{ml}(p<0.05)$ at $60 \mathrm{~min}$, then declined to near basal levels by $100 \mathrm{~min}$. Both the gastrectomy groups showed no significant increase of plasma SLI, despite a similar elevation of plasma FFA in these groups. Again, the basal plasma SLI levels showed no significant difference among these experimental groups.

\section{Discussion}

The present study reconfirms previous findings that an acute elevation of plasm FFA is a potent stimulus for secretion of SLI in dogs (Wasada et al. 1980) and humans (Beylot et al. 1984). Although the magnitude of elevation of plasma FFA in the present study is apparently supraphysiologic, FFA are likely related to the circulating SLI concentrations, as we had previously shown in alloxan diabetic dogs (Wasada et al. 1981). The ingestion of mixed meal is also an effective but relatively weak stimulus. Oral glucose and intravenous arginine led to no consistent increase in plasma SLI concentrations, though similar (Chayvialle et al. 1980 ; Conlon et al. 1983) or opposite results (Grill et al. 1984 ; Skare et al. 1984) were reported. Therefore, we employed the lipid-heparin test to examine plasma SLI response in gastrectomized subjects. In the present study, the lipidheparin test demonstrated a significant increase of plasma SLI in the normal controls but, in contrast, not in the gastrectomized subjects.

Taborsky and Ensinck (1984) assessed the contribution of the pancreas to circulating SLI in dogs. They measured not only the arterio-venous difference of 
SLI concentrations but also the organ blood flow, which allowed calculation of the net SLI output from the pancreas and gastrointestinal tract separately. Based on these data, they concluded that in normal dogs the pancreas made a negligible contribution to the basal and stimulated levels of SLI in arterial and portal venous plasma. So their conclusion seems to be supported by the present study, which done by a different way of approach in humans. In the present study, basal plasma SLI levels did not differ between the normal and gastrectomized subjects. The reason for this finding is not clear, but this is consistent with the results of Tsuda et al. (1981) in that in totally pancreatectomized or gastrectomized patients, fasting SLI levels did not differ from values in normal subjects. It may reflect a compensatory hypersecretion of SLI from the pancreas or extragastric intestinal tract.

The present study demonstrated that there was no difference in plasma SLI response between the subjects with total and antral gastrectomy, thereby suggesting that the antral region of the stomach seems to be a major source for plasma SLI under these experimental conditions. In fact, within the stomach the antrum was shown to contain a higher tissue concentration of SLI in dog (Kronheim et al. 1976) and humans (McIntosh et al. 1977). On the contrary, Chayvialle et al. (1980) observed similar SLI responses in normal dogs with an intact stomach and in dogs previously submitted to antrectomy and Billroth I anastomosis, when given a test meal. They concluded that antral $\mathrm{D}$ cells account for only part of the food-induced SLI response in dogs. The discrepancy of the results between theirs and ours may relate to the difference in species or stimuli used. Schusdziarra et al. (1979) demonstrated that truncal vagotomy did not alter significantly the meal-induced SLI rise in pancreatic venous plasma in anesthetized dogs. Therefore, our results are unlikely to be related to the influence of vagotomy.

Finally, we tested the effect of ingestion of a liquid mixed meal on the plasma SLI levels in the separate group of subjects with gastrectomy, but no consistent change in the plasma level of SLI was noted (data not shown).

In conclusion, provided that an elevation of plasma FFA stimulates pancreatic SLI in humans as previously shown in dogs (Wasada et al. 1980), the lack of a FF A-induced plasma SLI increase in the gastrectomized subjects favors the view that the stomach makes a greater contribution to the concentrations of circulating SLI than does the pancreas or extragastric intestinal tract in humans.

\section{References}

1) Beylot, M., Chayvialle, J.A., Riou, J.P., Souquet, J.C., Sautot, G., Cohen, R. \& Mornex, R. (1984) Regulation of somatostatin secretion in man: Study of the role of free fatty acids and ketone bodies. Metabolism, 33, 988-993.

2) Chayvialle, J.A., Miyata, M., Rayford, P.L. \& Thompson, J.C. (1980) Effects of test meal, intragastric nutrients and intraduodenal bile on plasma concentrations of immunoreactive somatostatin and vasoactive intestinal peptide in dogs. Gastroenterology, 79, 844-852. 
3) Conlon, J.M., Bridgeman, M. \& Alberti, K.G.M.M. (1982) The nature of big plasma somatostatin: implications for the measurement of somatostatin-like immunoreactivity in human plasma. Analyt. Biochem., 125, 243-252.

4) Conlon, J.M., McCulloch, A.J. \& Alberti, K.G.M.M. (1983) Circulating somatostatin concentrations in healthy and non-insulin-dependent (Type II) diabetic subjects. Diabetes, 32, 723-729.

5) Grill, V., Gutniak, M., Roovete, A. \& Efendic, S. (1984) A stimulating effect of glucose on somatostatin release is impaired in non-insulin-dependent diabetes mellitus. J. clin. Endocr. Metab., 59, 293-297.

6) Kronheim, S., Berelowitz, M. \& Pimstone, B.L. (1976) A radioimmunoassay for growth hormone release-inhibiting hormone: Method and quantitative tissue distribution. Clin. Endocr., 5, 619-630.

7) McIntosh, C., Arnold, R., Kobberling, J., Becker, H. \& Creutzfeld, W. (1977) Immunoreactive somatostatin in the gastrointestinal tract of dog and human. Europ. $J$. clin. Invest., 7, 252, (Abstract).

8) Schusdziarra, V., Harris, V., Conlon, J.M., Arimura, A. \& Unger, R.H. (1978) Pancreatic and gastric somatostatin release in response to intragastric and intraduodenal nutrients and HCL in the dog. $J$. clin. Invest., 62, 509-518.

9) Schusdziarra, V., Rouiller, D., Harris, V. \& Unger, R.H. (1979) Gastric and pancreatic release of somatostatin-like immunoreactivity during the gastric phase of a meal : Effects of truncal vagotomy and atropine in the anesthetized dog. Diabetes, 28, 658663.

10) Schusdziarra, V., Rouiller, D., Harris, V. \& Unger, R.H. (1981) Origin of peripheral hypersomatostatinemia in alloxan-diabetic dogs. Endocrinology, 109, 1107-1110.

11) Shimizu, S., Tani, Y., Yamada, H., Tabata, M. \& Murachi, T. (1980) Enzymatic determination of serum-free fatty acids : a colorimetric method. Analyt. Biochem., 107, 193-198.

12) Skare, S., Hanssen, K.F., Kriz, V. \& Torjensen, P.A. (1984) Arginine infusion increases peripheral somatostatin in man. Clin. Endocr., 21, 299-308.

13) Taborsky, G.J. \& Ensinck, J.W. (1984) Contribution of the pancreas to circulating somatostatin-like immunoreactivity in the normal dog. J. clin. Invest., 73, 216-223.

14) Tsuda, K., Sakurai, H., Seino, Y., Seino, S., Tanigawa, K., Kuzuya, H. \& Imura, H. (1981) Somatostatin-like immunoreactivity in human peripheral plasma measured by radioimmunoassay following affinity chromatography. Diabetes, 30, 471-474.

15) Wasada, T., Howard, B., Dobbs, R.E. \& Unger, R.H. (1980) Evidence for a role of free fatty acids in the regulation of somatostatin secretion in normal and alloxan diabetic dogs. J. clin. Invest., 66, 511-516.

16) Wasada, T., Howard, B., McCorkle, K., Harris, V. \& Unger, R.H. (1981) High plasma free fatty acid levels contribute to the hypersomatostatinemia of insulin deficiency. Diabetes, 30, 358-361.

17) Wass, J.A.H., Penman, E., Dryburgh, J.R., Tsiolakis, D., Goldberg, P.L., Dawson, A. M., Besser, G.M. \& Ress, L.H. (1980) Circulating somatostatin after food and glucorse in man. Clin. Endocr., 12, 569-574. 